\title{
DOES THE FAILURE TO PROVIDE EQUITABLE ACCESS TO TREATMENT LEAD TO ACTION BY NHS ORGANISATIONS? THE CASE OF BIOLOGICS FOR SOUTH ASIANS WITH INFLAMMATORY BOWEL DISEASE
}

\author{
Affifa Farrukh* John Francis Mayberry**
}

\section{ABSTRACT}

Aims: The purpose of this study was to identify whether NHS Trusts where discrimination in the delivery of care to patients from the South Asian community had been demonstrated had taken any actions to address the issue over the subsequent year.

Methods: Freedom of information requests were sent to three trusts which had provided evidence of disparate provision of biologic therapy to patients with Crohn's disease, their associated Clinical Commissioning Groups and HealthWatch organisations to seek evidence they had remedied the situation. Requests were also sent to the Care Quality Commission, NHS Improvement and the Equality and Human Rights Commission seeking examples where they had responded to inequitable delivery of care related to ethnicity.

Results: No organisation had any evidence of responses to the situation, many unable to accept its existence.

Conclusion: Legal duties are discussed and the only remedy appears to be through the tort of negligence.

Key Words: Discrimination, Ethnicity, Biologics, Inflammatory Bowel Disease

\section{INTRODUCTION}

Crohn's disease and ulcerative colitis are both chronic incurable inflammatory bowel diseases characterised by diarrhoea and abdominal pain. During the last two decades, these diseases have increased significantly in frequency and spread

\footnotetext{
Consultant Physician \& Gastroenterologist, Nuffield Hospital, Scraptoft Lane, Leicester, UK.

** Professor of Gastroenterology, Nuffield Hospital, Scraptoft Lane, Leicester, UK.
} 


\section{DOES THE FAILURE TO PROVIDE EQUITABLE ACCESS TO TREATMENT LEAD TO ACTION BY NHS ORGANISATIONS?}

throughout the world. ${ }^{1}$ Studies on migrant communities have shown them to be particularly susceptible to aggressive forms of chronic incurable inflammatory bowel disease, especially in the second generation. ${ }^{2,3}$ Their cause is unknown and so treatment is directed at control of symptoms rather than cure. Up until the end of the twentieth century, this treatment was limited to a small range of drugs or surgery. The drugs were low cost and surgery could involve significant resections of the bowel and also the formation of a permanent stoma. Both conditions also significantly increase the risk of developing colonic cancer. ${ }^{4,5}$ However, during the last decade there have been significant changes in the management of both Crohn's disease and ulcerative colitis with the introduction of monoclonal antibodies. These treatments are expensive, costing between $£ 12,000$ and $£ 15,000$ per year for the medications alone. Their use is approved by the National Institute for Health and Care Excellence (NICE) ${ }^{6,7}$ and this has had significant economic consequences for hospital trusts and Clinical Commissioning Groups (CCGs). The provision of these agents is regulated by a Technology Appraisal Guidance, which means that if they are indicated they must be provided to patients. The purpose of Technology Appraisal Guidance is 'to ensure that all NHS patients have equitable access to the most clinically- and cost-effective treatments that are available'.

1 SC Ng, HY Shi, N Hamidi, FE Underwood, et al., 'Worldwide Incidence and Prevalence of Inflammatory Bowel Disease in the $21^{\text {st }}$ Century: A Systematic Review of PopulationBased Studies' (2018) 390 Lancet 2769.

2 I Carr and JF Mayberry, 'The Effects of Migration on Ulcerative Colitis: A Three-Year Prospective Study among Europeans and First- and Second-Generation South Asians in Leicester (1991-1994)' (1999) 94 American Journal of Gastroenterology 2918.

3 A Farrukh and JF Mayberry, 'Inflammatory Bowel Disease and the South Asian Diaspora' (2019) JGH Open <https://doi.org/10.1002/jgh3.12149 > accessed 6 August 2019.

4 JA Eaden, KR Abrams and JF Mayberry, 'The Risk of Colorectal Cancer in Ulcerative Colitis: A Meta-Analysis' (2001) 48 Gut 526.

5 C Canavan, KR Abrams and J Mayberry, 'Meta-Analysis: Colorectal and Small Bowel Cancer Risk in Patients with Crohn's Disease' (2006) 23 Alimentary Pharmacology and Therapeutics 1097.

6 NICE, 'Infliximab and Aalumimab for the Treatment of Crohn's disease' (NICE, 2010) <nice.org.uk/guidance/ta187> accessed 14 May 2019.

7 NICE, 'Infliximab, Adalumimab and Golumimab for Treating Moderately to Severely Active Ulcerative Colitis after the Failure of Conventional Therapy' (NICE, 2015) < nice. org.uk/guidance/ta329> accessed 22 November 2016.

8 NICE, 'Summary of Technology Appraisal Decisions' (NICE, 2016) < nice.org.uk/ about/what-we-do/our-programmes/nice-guidance/nice-technology-appraisal-guidance/ summary-of-decisions $>$ accessed 22 November 2016. 
Discrimination in the delivery of care has long been recognised in the United States, but during the last 20 years it has become apparent that this is also true in the United Kingdom. ${ }^{9}$ Recent studies have highlighted evidence that South Asian patients have less access to these medications. ${ }^{10}$ A study in Leicester demonstrated that South Asian patients with Crohn's disease were four times less likely to receive biologic therapy than their English counterparts. ${ }^{11}$ This difference was independent of gender and accounted for age differences between the two communities. A subsequent study looked at the provision of biologic therapy for Crohn's disease in 10 English NHS Trusts, which served areas with the largest ethnic variation. ${ }^{12}$ The Freedom of Information (FOI) request revealed that in three trusts, Pennine Acute Hospitals NHS Trust covering Oldham and North Manchester, Barking, Havering \& Redbridge University Hospitals NHS Trust and University Hospitals of Leicester NHS Trust, South Asian patients with Crohn's disease were significantly less likely to receive biologic therapy than English patients. One trust, Bradford Teaching Hospitals NHS Foundation Trust, declined to provide information on the basis that it did not collect data on ethnicity. In the remaining trusts there was no evidence of minority populations being underserved. In ulcerative colitis a review of the management of patients over the decade following their initial diagnosis showed that South Asian patients were less likely to be seen by a consultant, less likely to be investigated and more likely to be discharged from hospital based care. ${ }^{13}$ There is supportive evidence for such findings from the United States, where discrimination in the delivery of care to ethnic minorities has been long recognised. ${ }^{14}$ In the 1990s the American Medical

\footnotetext{
9 NICE (n 8).
}

10 A Farrukh and J Mayberry, 'Ethnic Variations in the Provision of Biologic Therapy for Crohn's Disease: A Freedom of Information Study' (2015) 83 Medico-Legal Journal 104; A Farrukh and JF Mayberry, 'Apparent Discrimination in the Provision of Biologic Therapy to Patients with Crohn's Disease According to Ethnicity' (2015) 129 Public Health 460; A Farrukh and JF Mayberry, 'Patients with Ulcerative Colitis from Diverse Populations: The Leicester Experience' (2016) 84 Medico Legal Journal 31; A Farrukh and JF Mayberry, 'Evidences of Differences and Discrimination in the Delivery of Care: Colorectal Screening in Healthy People and in the Care and Surveillance of Patients with Inflammatory Bowel Disease' (2019) 1 Gastrointestinal Disorders 253.

11 Farrukh and Mayberry (n 12).

12 Ibid.

13 Farrukh and Mayberry (n 12).

14 JF Jackson III, T Dhere, A Repaka, A Shaukat and S Sitaraman, 'Crohn's Disease in an African-American Population' (2008) 336 American Journal of Medical Sciences 389; MH Flasar, T Johnson, MC Roghmann and RK Cross, 'Disparities in the Use of Immunomodulators and Biologics for the Treatment of Inflammatory Bowel Disease: A 


\section{DOES THE FAILURE TO PROVIDE EQUITABLE ACCESS TO TREATMENT LEAD TO ACTION BY NHS ORGANISATIONS?}

Association recognised that 'subconscious bias' may be a factor for such clinical practice. ${ }^{15}$ In the United States, Geiger has attributed such differences in care to either 'conscious bias or, more often, unconscious negative stereotyping' ${ }^{16}$. There are no other ready explanations for such differences in the care of patients with inflammatory bowel disease in the United Kingdom. The diseases occur with equal severity in patients of South Asian and English origin, and the studies discussed above compensated for differences in age structure between communities, indicating that the differences in standards of care are real.

The three trusts where patients received disparate care were informed of the results through a range of methods including presentations and publications. The purpose of this study was to investigate the practical responses of Pennine Acute Hospitals NHS Trust, Barking, Havering \& Redbridge University Hospitals NHS Trust and University Hospitals of Leicester NHS Trust, to these findings one year later. Related organisations concerned with the delivery of care by these trusts were also contacted to assess what action they had taken. These organisations fell into two groups, namely local and national. Local groups included the Clinical Commissioning Groups (CCGs) and the Health and Well-Being Boards, while national organisations contacted were the Care Quality Commission, NHS Improvement and the Equality and Human Rights Commission. CCGs are clinically led statutory NHS bodies responsible for the planning and commissioning of health care services for their local area. Health and Well-Being Boards commission local HealthWatch organisations. They are a statutory service set up by local councils as part of the Health and Social Care Act 2012. HealthWatch describes its role as:

... the independent national champion for people who use health and social care services. We're here to make sure that those running services, and the government, put people at the heart of care. ${ }^{17}$

Retrospective Cohort Study' (2008) 14 Inflammatory Bowel Disease 13; OM Damas, DA Jahann, R Reznik, JL McCauley, L Tamariz, AR Deshpande, MT Abreu and DA Sussman, 'Phenotypic Manifestations of Inflammatory Bowel Disease Differ between Hispanics and Non-Hispanic Whites: Results of a Large Cohort Study' (2013) 108 American Journal of Gastroenterology 231.

15 Council on Ethical and Judicial Affairs American Medical Association, 'Black-White Disparities in Health Care' (1990) 263 Journal of the American Medical Association 2344.

16 HJ Geiger, 'Racial and Ethnic Disparities in Diagnosis and Treatment: A Review of the Evidence and Consideration of Causes' (2003) in BD Smedley, AY Stith and AR Nelson (eds), Unequal Treatment Confronting Racial and Ethnic Disparities in Healthcare (The National Academies Press Washington 2003).

17 HealthWatch (2019) <healthwatch.co.uk/what-we-do> accessed 13 May/2019. 
Each trust is linked with several CCGs and HealthWatch groups, representing different areas which they serve.

The method adopted in this study was to approach each of the three trusts where there was evidence of underserving members of the ethnic minority community who had inflammatory bowel disease. In addition those bodies who have a statutory duty to monitor their delivery of service were also approached. On a local basis this was the CCGs and HealthWatch organisations and nationally CQC, NHS Improvement and EHRC. The technique chosen was to submit a Freedom of Information (FOI) request, as this allowed follow-up questions, when answers lacked clarity. Some authors have expressed the hope that greater transparency in health care will lead to improved services and that FOIs could be one engine for such a change. ${ }^{18}$ However, the effectiveness of FOI ultimately depends upon the attitude and commitment with which it is approached by government agencies and their staff as well as public insistence that the statute is implemented in a way which fulfils its purpose. $^{19}$

\section{STUDY}

In this study FOI requests were sent to:

1. The three NHS Trusts which had treated fewer South Asian patients than expected, namely Pennine Acute Hospitals NHS Trust, Barking, Havering \& Redbridge University Hospitals NHS Trust and University Hospitals of Leicester NHS Trust

2. The Clinical Commissioning Groups (CCGs) and HealthWatch groups commissioned by Health and Wellbeing Boards associated with these three Trusts

3. Care Quality Commission (CQC)

4. NHS Improvement (formerly Monitor)

5. Equality and Human Rights Commission (EHRCC)

18 AJ Fowler, RA Agha RA, CF Camm and P Littlejohns, 'The UK Freedom of Information Act (2000) in Healthcare Research: A Systematic Review' (2013) BMJ Open $<$ 10.1136/bmjopen-2013-002967> accessed 6 August 2019.

19 M Berger, 'The Freedom of Information Act: Implications for Public Health Policy and Practice' (2011) 126 Public Health Reports 428. 
NHS Trusts, CCGs and HealthWatch groups were asked to respond to two questions related to the information and published work on disparate care. They were:

1. What actions have the Trust/CCG//HealthWatch taken to ensure equitable access by the South Asian community and other minority groups to treatment with biologics for inflammatory bowel disease?

2. What monitoring systems does the Trust/CCG/HealthWatch have in place to ensure equitable access to treatment with biologics by patients from the South Asian community and other minority groups?

Groups which failed to reply were sent a further request. Where answers were unclear or ambiguous explanations were sought.

The CQC, NHS Improvement and the EHRC were asked:

'Can you provide a list of the interventions that the CQC/Monitor or NHS Improvement/EHRC have made when there has been evidence of discrimination in the delivery of care to patients in the NHS based on ethnicity?'

Again where answers were unclear or appeared evasive respondents were asked to expand or clarify their response.

Responses were reviewed for common themes using content analysis. ${ }^{20}$ This technique has previously been used in data drawn from multiple sources, including relatively short extracts. ${ }^{21}$

Responses were received from the three NHS Trusts, six CCGs but only one HealthWatch. Those 10 organisations which replied provided answers to all of the questions posed to them. Many of the responses from different organisations across the country were carbon copies of each other, raising the possibility that Freedom of Information requests are responded to with standard answers and hence the need to seek clarification in some cases. The common themes identified from responses were:

1. There is no discrimination in the delivery of care and we deliver clinically appropriate treatment to all patients. This theme was present in responses from all 10 organisations.

20 GW Ryan and HR Bernard, 'Techniques to Identify Themes' (2003) 15 Field Methods 85; K Krippendorff, Content Analysis: An Introduction to Its Methodology (2nd edn, 2004 Sage).

21 JF Mayberry, 'An Analysis of Blogs from Medical Students on "English Parallel" Courses in Central and Eastern Europe’ (2013) 81 Medico Legal Journal 171. 
2. There is no mechanism for routine monitoring whether there is any discrimination in the delivery of care. The data we collect on treatment and ethnicity is too large to allow any analysis. This theme was seen in responses from all NHS Trusts and CCGs

3. The organisation depends upon complaints about discrimination to initiate action and it has not received any. This theme was identified in the response from the HealthWatch organisation.

Examples of responses to Question 1 included:

'We can confirm that all our patients are treated without discrimination'.

'It would be both difficult and unlikely for there not to be equitable access to biologic therapy'.

'The Trust only starts patients on biologics according to strict clinical criteria'.

No trust had responded to the published findings based on evidence they had supplied through earlier Freedom of Information requests.

Answers to Question 2 included:

'It is not considered that there is an access issue within name of organisation'.

CCGs stated they were unable to access relevant data. However, if they became aware that:

access is especially focussed on or restricted amongst particular ethnic groups, then the CCGs would take this issue very seriously and issue a Contract Performance Notice.

The need to monitor equality of access to care is a specific requirement of contracts between CCGs and Trusts and is an obligation on both organisations. The second question addressed this requirement. None of the respondents had any monitoring system in place. Indeed, most organisations tacitly recognised that monitoring equality in delivery of care did not occur. HealthWatch Oldham replied that it had:

a number of systems in place for monitoring Oldham residents' access to and experience of health and social care services. These include a broad survey of patient experiences as well as using information from NHS Choices, Patient Opinion and the Care Quality Commission. 


\section{DOES THE FAILURE TO PROVIDE EQUITABLE ACCESS TO TREATMENT LEAD TO ACTION BY NHS ORGANISATIONS?}

The common themes reported by CQC and NHS Improvement included:

1. The information cannot be readily accessed from our data collection.

2. It is not within our Terms of Reference; some other body is responsible.

The CQC reported that it would not issue a warning notice for the scenario described in the question as such notices are only used for systemic failures. It went on to state that enforcement actions were on the basis of contravention of Regulations 9, 10 and 17 of the Health and Social Care Act 2008 (Regulated Activities) Regulations 2014. To determine whether breaches of these regulations related to disparity in delivery of care based on ethnicity each action would need to be manually reviewed and the CQC was unwilling to conduct such an exercise. Regulation 9 states:

1. The care and treatment of service users must-

a. be appropriate,

b. meet their needs; and

c. reflect their preferences.

2. Without limiting paragraph (1), the things which a registered person must do to comply with that paragraph include-

a. carrying out, collaboratively with the relevant person, an assessment of the needs and preferences for care and treatment of the service user;

b. designing care or treatment with a view to achieving service users' preferences and ensuring their needs are met.

and Regulation 17:

2(e) seek and act on feedback from relevant persons and other persons on the services provided in the carrying on of the regulated activity, for the purposes of continually evaluating and improving such services.

Clearly the underserving of ethnic minorities by Trusts falls within these categories and it is of concern that the CQC did not consider that this represented a systems failure and falls clearly within the grounds for issuing a warning notice. The failure of the CQC to deal with underperformance in a trust has previously been identified in a report by Grant Thornton on University Hospital of Morecombe Bay where it concluded that there had, on the balance of probabilities, been 'an attempt to cover-up matters concerning CQC's regulation of UHMB'. ${ }^{22}$

22 Grant Thornton, 'The Care Quality Commission re: Project Ambrose dated 14 June 
NHS Improvement's response was that it held some logs of its work but they:

do not go into sufficient granularity to specify whether any of those actions were based on any concerns relating to discrimination based on ethnicity. Please note that NHS Improvement does not have a role in monitoring trusts' compliance with equalities legislation.

This is despite the fact that from 2014 it was tasked with issuing NHS Provider Licences to Trusts providing clinical care. Among the conditions for licenses were:

4 (a) improving the quality of health care services provided for the purposes of the NHS (...) or the efficiency of their provision, (b) reducing inequalities between persons with respect to their ability to access those services, and (c) reducing inequalities between persons with respect to the outcomes achieved for them by the provision of those services. ${ }^{23}$

The EHRC considered such issues did fall within its Terms of Reference but reported that:

Following a search of the Commission's Section 30 intervention records, we have determined that we hold no information relevant to your request.

\section{DISCUSSION}

Trusts and their associated bodies are unwilling to accept that there is discrimination in the delivery of care, despite the fact that this has been shown through independent analysis of their own data. Although they have collected these data they consider them too large to allow any analysis and have no structures in place to monitor whether they are delivering an equitable service. Rather they depend upon external complaints by patients about discrimination being made to them, and they deny having received any. In addition, there is no evidence that any NHS Trust or CCG where there was disparate care in delivery of biologics has taken any action to remedy the situation.

2013'<cqc.org.uk/sites/default/files/media/documents/grant_thornton_uk_llp_morecambe_ bay.pdf $>$ accessed 13 May 2019.

23 Monitor, 'The New NHS Provider Licence' (2013) <gov.uk/government/uploads/ system/uploads/attachment_data/file/285008/ToPublishLicenceDoc14February.pdf> accessed 1 December 2016. 


\section{DOES THE FAILURE TO PROVIDE EQUITABLE ACCESS TO TREATMENT LEAD TO ACTION BY NHS ORGANISATIONS?}

\section{There Is No Discrimination in the Delivery of Care}

Despite the responses from the three NHS trusts and their associated CCGs problems with the equitable delivery of care in the secondary sector are widespread. The situation demonstrated for South Asian patients with inflammatory bowel disease is not unusual. Other examples include Black African women with breast cancer being less likely to have surgery and more likely to be simply offered chemotherapy, while Pakistani women were less likely to be offered radiotherapy or hormone treatment than White women. ${ }^{24}$ In the twenty-first century ethnic minority patients on the renal transplant register are still less likely to receive a donor organ than White patients. ${ }^{25}$ In the field of mental health Black service users tend to be given injectable depot treatments rather than offered tablets or cognitive behavioural therapy. ${ }^{26}$ Further examples include a qualitative study of registered nurses working in hospitals in Leeds which identified racism affecting their care of Pakistani patients. ${ }^{27}$ Earlier a group of South Asian inpatients had described how they felt that they needed to fit into what they described as an 'English place'. ${ }^{28}$ In another study from Middlesborough, only 5\% of Pakistani patients were told of the availability of professional translators to help with consultations. ${ }^{29}$

24 RH Jack, EA Davies and H Møller, 'Breast Cancer Incidence, Stage, Treatment and Survival in Ethnic Groups in South East England' (2009) 100 British Journal of Cancer 545.

25 U Udavaraj, R Pruthi, A Casula and P Roderick, 'UK Renal Registry 16th Annual Report: Chapter 6 Demographics and Outcomes of Patients from Different Ethnic Groups on Renal Replacement Therapy in the UK' (2013) 125 Nephron Clinical Practice 111.

26 J Das-Munshi, D Bhugra and MJ Crawford, 'Ethnic Minority Inequalities in Access to Treatments for Schizophrenia and Schizoaffective Disorders: Findings from a Nationally Representative Cross-Sectional Study' (2018) 16 BMC Medicine 55.

27 JD Cortis, 'Meeting the Needs of Minority Ethnic Patients' (2004) 48 Journal of Advanced Nursing 51.

28 V Vydelingum, 'South Asian Patients' Lived Experience of Acute Care in an English Hospital: A Phenomenological Study' (2000) 32 Journal of Advanced Nursing 100.

29 R Madhok, A Hameed and R Bhopal, 'Satisfaction with Health Services among the Pakistani Population in Middlesborough, England' (1998) 20 Journal of Public Health Medicine 295. 


\section{There Is No Mechanism for Routine Monitoring for Discrimination in the Delivery of Care}

The Equality Impact Analysis for the NHS for 2016 and for 2017-2018 states that:

The main types of data and information that evidence inequalities relate to:

- patient access to services, experience and health outcomes. ${ }^{30,31,32}$

Although Trusts are contracted to collect these data they have wide latitude in how this is done but are expected to seek out additional sources of information related to equality of care. Such sources should include published work as well as direct presentations. The guidance that is available on commissioning to reduce inequalities notes that local need is an essential factor to be aware of. ${ }^{33}$ However, failure to collect and monitor information on patient ethnicity is widespread. In the Race Equality Service Review only 9 of 24 trusts collected such data. However, only 3 of the 15 who failed to collect the data admitted to doing so. ${ }^{34}$ Denial, as in this study on the underserving of South Asian patients, is the standard response to many requests to NHS organisations for information about ethnicity. Indeed a recent study of three Primary Care Trusts in the North of England found that:

Rather than being embedded within processes of understanding and responding to the health care needs of the local population, ethnic (and other) equalities work was generally constructed as a matter of legal compliance or, as one respondent explained, a nicety, not a necessity. ${ }^{35}$

30 NHS, 'A refreshed Equality Delivery System for the NHS EDS2 Making Sure That Everyone Counts' (2013) <england.nhs.uk/wp-content/uploads/2013/11/eds-nov131.pdf> accessed 14 May 2019.

31 NHS England, 'NHS Standard Contracts 2016/17 Equality Impact Analysis' (2016) <england.nhs.uk/wp-content/uploads/2016/03/nhs-std-con-eia.pdf> accessed 14 May 2019.

32 NHS England, 'NHS Standard Contracts 2017/18 and 2018/19 Equality Impact Analysis' (2016) <england.nhs.uk/wp-content/uploads/2016/12/nhs-std-contract-eia-1718. pdf $>$ accessed 29 January 2017.

33 Dr Foster Intelligence, The Intelligent Board 2009: Commissioning to Reduce Inequalities (Dr Foster Intelligence 2009).

34 V Lyfar-Cisse, Race Equality Service Review (South East Coast BME Network 2008).

35 S Salway, G Mir D Turner, GT Ellison, L Carter and K Gerrish, 'Obstacles to "Race 


\section{The Organisation Depends upon Complaints about Discrimination to Initiate Action}

In 2015 the Health Select Committee has described the NHS complaints system in the following terms:

....Too many complaints are mishandled with people encountering poor communication or, at worst, a defensive and complicated system which results in a complete breakdown in trust and a failure to improve patient safety. ${ }^{36}$

The problem which this study has identified is that apparently none of the trusts have received any complaints indicating that their treatment policies were discriminatory. The complicated nature of the complaints system makes this not surprising. Indeed even the EHRC has had limited involvement with health care and unequal treatment related to protected characteristics. One of the few examples that has been reported was the formal agreement it made with NHS Tayside. ${ }^{37}$ Its purpose was to ensure that all deaf patients would have their communication needs met.

\section{GENERAL COMMENTS}

One of the roles of NICE is to ensure that effective medications are available to patients and the specific purpose of its Technology Appraisal Guidance is:

......to reduce variations in practice across the country.... ${ }^{38}$

These powers are set out in Regulation 7 of Statutory Instrument 2013 No. 259 which states:

7 ((6) A relevant health body must comply with a technology appraisal recommendation.

Equality" in the English National Health Service: Insights from the Healthcare Commissioning Arena' (2016) 152 Social Science \& Medicine 102.

36 Health Select Committee, Complaints and Raising Concerns (HC 2014-2015, 350) para 3.

37 Equality and Human Rights Commission, 'Section 23 Agreement between the Equality and Human Rights Commission and Tayside Health Board This Agreement dated 7 October 2014' <nhstaysidecdn.scot.nhs.uk> accessed 11 April 2017.

38 NICE, 'Charter' (2013) <nice.org.uk/Media/Default/About/Who-we-are/NICE_ Charter.pdf $>$ accessed 22 November 2016. 


\section{THE DENNING LAW JOURNAL}

Within its Quality Standard for Inflammatory Bowel Disease NICE also recognised:

Commissioners and providers should aim to achieve the quality standard in their local context, in light of their duties to have due regard to the need to eliminate unlawful discrimination. ${ }^{39}$

Monitor and CQC are charged with supervising the overall functioning of hospitals, but their inspections do not drill down into adherence to individual Guidance. However, in an obiter dicta in Rose v Thanet Clinical Commissioning Group, Mr Justice Jay said:

......The extent of the public law obligation is to have regard to the relevant NICE guideline and to provide clear reasons for any general policy that does not follow it... ${ }^{40}$

The NHS Litigation Authority has recognised the need for organisations to have mechanisms for monitoring implementation of NICE Guidelines. ${ }^{41}$ Where a Trust fails to do so, it is conceivable that a judicial review could require that organisation to reformulate its policies. Medical Directors were given responsibility for implementation and so failures might raise questions concerning their fitness to practice and lead to referral to the GMC. However, the question remains as to who would seek such a review or make such a referral.

The Public Sector Equality Duty identified in the Equality Act is the basis for the statement in the NHS Constitution that:

Legal duties require NHS England and each clinical commissioning group to have regard to the need to reduce inequalities in access to health services and the outcomes achieved for patients. ${ }^{42}$

\footnotetext{
39 NICE, 'Inflammatory Bowel Disease' (2015) < nice.org.uk/guidance/qs81> accessed 14 May 2019.

40 [2014] EWHC 1182 (Admin).

41 NHS Litigation Authority, 'An Organisation-Wide Document for the Dissemination, Implementation and Monitoring of NICE Guidance' (2012) < nhsla.com/.../Document\%20 for\%20the\%20Dissemination\%20Implementation\%> accessed 1 December 2016.

42 Department of Health, 'Guidance: The NHS Constitution for England' (2015) < gov. uk/government/publications/the-nhs-constitution-for-england/the-nhs-constitution-forengland > accessed 14 May 2019.
} 


\section{DOES THE FAILURE TO PROVIDE EQUITABLE ACCESS TO TREATMENT LEAD TO ACTION BY NHS ORGANISATIONS?}

Sections 212 and 213 of the Act make it clear that omission carries the same legal consequences as a requirement to perform a service. In 2013 Monitor was tasked with issuing Provider Licences to Trusts and among the conditions is:

... 4 (b) reducing inequalities between persons with respect to their ability to access those services.... ${ }^{43}$

Monitor has been subsumed within NHS Improvement, but the organisation's response was:

... Please note that NHS Improvement does not have a role in monitoring trusts' compliance with equalities legislation.

Which COMMENT suggests it is unaware of its responsibilities under 4(b). Unfortunately, section 71 of the Health and Social Care Act (2012) provides no remedy to the ordinary citizen if Monitor fails in performance of its functions.

CQC considers its objectives are to:

... help to focus providers and commissioners on the importance of their responsibilities towards equality, diversity and human rights, and to improvement ${ }^{44}$

and ensure:

$\ldots$ an organisation provides services proportionately to different groups and their needs ${ }^{45}$

So it is disappointing that $\mathrm{CQC}$ is unable to readily identify any occasion when it has issued enforcement actions concerned with inequality in delivery of care related to ethnic diversity.

The Health and Social Care Act 2012 created Health and Social Welfare Boards to ensure local needs were met. However, such Boards lack formal powers

\footnotetext{
43 Monitor, 'The New NHS Provider Licence' (2013) <gov.uk/government/uploads/ system/uploads/attachment_data/file/285008/ToPublishLicenceDoc14February.pdf> accessed 14 May 2019.

${ }^{44}$ Care Quality Commission, 'Equality and Human Rights Impact Assessment' (EHRIA, 2010) <cqc.org.uk/sites/default/files/documents/20100630_31_assessments_of_quality_ eia_pub_version.pdf $>$ accessed 14 May 2019.

45 Ibid.
} 
to instruct CCGs or NHS Trusts and by building good relationships hope to influence decisions by these bodies. Their present role appears little more than that of a talking shop.

The question as to why Trusts and related organisations have failed to respond to the evidence of discrimination in the delivery of care is critical to any future actions to improve the situation. Interestingly in an earlier study of English Primary Care Trusts Salway et al. found that

......consideration of ethnicity was often treated as a matter of legal compliance rather than ntegral to understanding and meeting healthcare needs. Many managers and teams did not consider tackling ethnic healthcare inequities to be part-and-parcel of their job, lacked confidence and skills to do so, and questioned the legitimacy of such work..... ${ }^{46}$

The questioning of the legitimacy of such findings is common to this report. None of the respondent organisations identified any attempt by management to address these issues, often on the basis that they simply could not be true. DilworthAnderson et al. ${ }^{47}$ (48) have suggested that in the US cultural interpretation of disease plays a central role with disparities in care being attributed to perceived rather than real differences and so legitimising a 'Do nothing' approach, because nothing needed to be done.

\section{CONCLUSION}

So where lies hope for a disadvantaged group of patients? Sadly the most likely route for individuals is through the tort of negligence. Clearly there will have been a breach of duty and but for that breach patients would have experienced a better quality of life through use of biologics and there is emerging data that their disease may have followed a different course. Any current hope that there will be management-driven changes or interventions by regulatory bodies seems forlorn.

\footnotetext{
46 Salway et al (n 37).

47 P Dilworth-Anderson, G Pierre and TS Hilliard, 'Social Justice, Health Disparities, and Culture in the Care of the Elderly' (2012) 152 Journal of Law \& Medical Ethics 26.
} 